and wk12 (-20.5\% vs $-12.2 \%)$, although the differences were not statistically significant.

FIL and ADA caused differential patterns of cytokine response at either wks 4 or 12. Of 12 biomarkers with a significant FIL200mg+MTX treatment effect, there was a significantly larger reduction in TNFSF13B and CTX1 relative to ADA+MTX at 12 wks. Of 8 biomarkers with FIL100mg+MTX effects, only 2 (CXCL10 at wk 4; CXCL13 at wks 4 and 12) had significant differences from ADA+MTX. Relative either to FIL200mg+MTX or FIL100mg+MTX, and despite the same direction of effect, ADA+MTX led to a significantly larger reduction in CCL2, CXCL10, CCL4, and $\mathrm{CXCL} 13$.

Conclusion: Compared with PBO, 12 wks of FIL treatment significantly reduced cytokines associated with JAK activity ${ }^{1}$, bone biology ${ }^{2}$, inflammation ${ }^{2}$, and immune cell migration ${ }^{2}$ in MTX-IR pts. The effects were largely FIL dose-dependent; most cytokines exhibited similar effects regardless of treatment arms, but differential changes between FIL+MTX and ADA+MTX were observed, supportive of the different mechanisms of action of these therapies.

References:

[1] Majoros A, et al. Front Immunol. 2017;8:29

[2] Brennan F, and McInnes I. J Clin Invest. 2008;118:3537-45

Acknowledgments: This study was funded by Gilead Sciences, Inc. Editorial support was provided by Fishawack Communications Inc and funded by Gilead Sciences, Inc.

Disclosure of Interests: Peter C. Taylor Grant/research support from: Celgene, Eli Lilly and Company, Galapagos, and Gilead, Consultant of: AbbVie, Biogen, Eli Lilly and Company, Fresenius, Galapagos, Gilead, GlaxoSmithKline, Janssen, Nordic Pharma, Pfizer Roche, and UCB, Emon Elboudwarej Shareholder of: Gilead Sciences Inc., Employee of: Gilead Sciences Inc., Bryan Downie Shareholder of: Gilead Sciences Inc., Employee of: Gilead Sciences Inc., Jinfeng Liu Shareholder of: Gilead Sciences Inc., Roche, Employee of: Gilead Sciences Inc., Rachael E. Hawtin Shareholder of: Gilead Sciences Inc., Employee of: Gilead Sciences Inc., Amer M. Mirza Shareholder of: Gilead Sciences Inc., Employee of: Gilead Sciences Inc.

DOI: 10.1136/annrheumdis-2020-eular.4704

\section{FRI0137 DISCONTINUATION OF BARICITINIB AFTER ACHIEVING LOW DISEASE ACTIVITY IN PATIENTS WITH RHEUMATOID ARTHRITIS IN CLINICAL PRACTICE; A MULTICENTER OBSERVATIONAL STUDY.}

E. Torikai ${ }^{1}$, Y. Hirano ${ }^{2}$, D. Suzuki ${ }^{3}$, Y. Kanayama ${ }^{4} .{ }^{1}$ I wata city hospital, Iwata, Japan; ${ }^{2}$ Toyohashi Municipal Hospital, Toyohashi, Japan; ${ }^{3}$ Futaba clinic, Iwata, Japan; ${ }^{4}$ Toyota Kosei Hopital, Toyota, Japan

Background: Baricitinib (bari) is an oral Janus kinase (JAK) 1/JAK2 selective inhibitor that has shown good efficacy in patients with RA and adequate response to conventional synthetic DMARDs in some clinical trials [1,2]. However, concerning the high cost and long-term safety related to the inhibition of particular molecules, we would like to discontinue bari after achieving long low disease activity (LDA).

Objectives: To evaluate the clinical outcomes in patients with RA who discontinued bari after achieving LDA for 24 weeks in real-world multicenter clinical data.

Methods: Japanese 67 patients with RA who show an inadequate response to csDMARDs or bDMARDs were scheduled to receive bari 4 or $2 \mathrm{mg} / \mathrm{day}$ once daily dose as a monotherapy or in combination with other csDMARDs. We included 51 patients who achieved and maintained LDA at least for 24 weeks after baricitinib therapy. They were allowed to decrease baricitinib after discontinuation of prednisolone. Bari was either discontinued or continued after study enrolment. The decision of discontinuation and continuation of baricitinib was determined based on patient-physician decision making with informed consent. We divided patients into two groups: a discontinuation group ( $D$ group; $n=23$ ) and a continuation group ( $C$ group; $n=28$ ). We evaluated the proportion of patients who remained LDA for 24 weeks in both groups. Clinical outcomes including Clinical Disease Activity Index (CDAI), and HAQ-DI were compared between both groups. The last observational carried forward method was used for patients who could not discontinue baricitinib due to flare before 24 weeks. In D group, patients were treated with re-initiation of bari or initiation of the other DMARDs in the event of flare. We investigated the serial changes of patients treated with re-initiation of bari in CDAl after flare.

Results: The baseline characteristics of the patients are summarized in Table. The titer of RF was lower in D group than that in $\mathrm{C}$ group. There were no significant differences in any other items. Ten of $23(43.4 \%)$ in D group remained bari-free without disease activity flare. Serial changes of CDAI were summarized in Figure. CDAI in D group significantly increased from 3.6 at baseline to 9.8 at last observation. LDA rates in $\mathrm{C}$ group were $92.9 \%$ at last observation. CDAI in $\mathrm{C}$ group did not change throughout the follow-up period. CDAl at last observation was higher in $\mathrm{D}$ group than that in $\mathrm{C}$ group. HAQ-DI in D group changed from 0.28 at baseline to 0.45 at last observation. There was no significant change in $\mathrm{HAQ}-\mathrm{DI}$ between both groups $(P=0.28)$. In $D$ group, rescue by re-administration of bari or other DMARDs induced improvement, reducing CDAI from 15.5 at disease flare to 6.8. Especially, all patients treated with re-initiation of bari resulted in re-introduction of LDA in this study.

Table. Characteristics of patients at baricitinib initiation

\begin{tabular}{lccc}
\hline & D group $(\mathrm{n}=23)$ & C group $(\mathrm{n}=28)$ & p-value \\
\hline Age (years) & $66.9(8.6)$ & $67.9(12.7)$ & 0.31 \\
Gender, female, $\mathrm{n}(\%)$ & $6(73.9)$ & $24(85.7)$ & 0.49 \\
Disease duration (years) & $7.6(10.3)$ & $8.3(9.9)$ & 0.37 \\
Prior use of biologics, $\mathrm{n}(0 / 1 / 2 / \geq 3)$ & $(21 / 2 / 0 / 0)$ & $(17 / 6 / 4 / 1)$ & --- \\
MTX (mg/w) & $5.5(3.8)$ & $4.9(4.3)$ & 0.62 \\
PSL $(\mathrm{mg} / \mathrm{d})$ & $1.4(1.9)$ & $0.9(0.9)$ & 0.51 \\
RF, U/ml & $99(141)$ & $187(214)$ & 0.04 \\
ACPA, U/ml & $135(173)$ & $194(214)$ & 0.11 \\
CDAl & $24.4(9.2)$ & $22.5(9.7)$ & 0.36 \\
HAQ-DI & $0.83(0.49)$ & $0.83(0.52)$ & 0.98
\end{tabular}

Figure
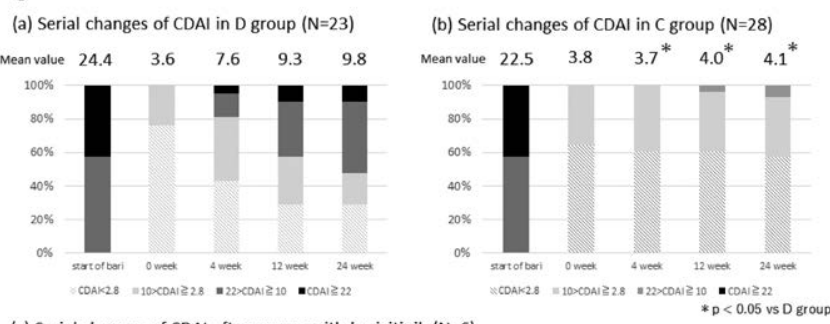

(c) Serial changes of CDAl after rescue with baricitinib $(\mathrm{N}=6)$

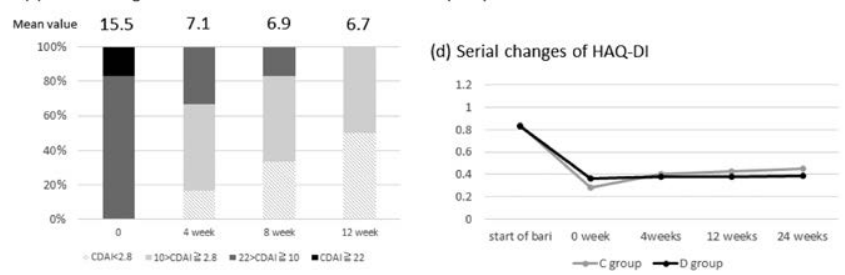

Conclusion: It was possible to discontinue bari without flare in about $43 \%$ of patients with RA. Overall the patients treated with re-initiation of bari could result in re-introduction of LDA without deterioration of HAQ-DI.

\section{References:}

[1] Tanaka $Y$ et al. Mod Rheumatol. 2018;28:583-91

[2] Tanaka Y et al. Mod Rheumatol. 2018;28:20-9

Disclosure of Interests: Eiji Torikai: None declared, Yuji Hirano Speakers bureau: Tanabe-Mitsubishi, Pfizer, Eisai, Abbie, Chugai, Bristol-Meyers, Jansen, Astellas, UCB, Eli-Lilly, Asahikasei, Daiichi-Sankyo, Amgen, Daisuke Suzuki: None declared, Yasuhide Kanayama: None declared DOI: 10.1136/annrheumdis-2020-eular.1546

\section{\begin{tabular}{|l|l|l|l}
\hline FRI0138 & THE IMPACT OF UPADACITINIB VERSUS
\end{tabular} METHOTREXATE OR ADALIMUMAB ON INDIVIDUAL AND COMPOSITE DISEASE MEASURES IN PATIENTS WITH RHEUMATOID ARTHRITIS}

R. Van Vollenhoven ${ }^{1}$, A. Ostor ${ }^{2}$, E. Mysler ${ }^{3}$, N. Damjanov ${ }^{4}$, I. H. Song ${ }^{5}$, Y. Song ${ }^{5}$ J. Suboticki ${ }^{5}$, V. Strand ${ }^{6}{ }^{1}$ Amsterdam Rheumatology and Immunology Center ARC, Amsterdam, Netherlands; ${ }^{2}$ Cabrini Medical Centre, Monash University, Malvern, Australia; ${ }^{3}$ Organización Medica de Investigación, Buenos Aires, Argentina; ${ }^{4}$ Institute of Rheumatology, Belgrade University School of Medicine, Belgrade, Serbia; ${ }^{5}$ AbbVie Inc., North Chicago, United States of America; ${ }^{6}$ Division of Immunology/Rheumatology, Stanford University, Palo Alto, United States of America 